perhaps but a semitone's alteration of pitch, is often most surprising. It was these sudden kaleidoscopic bounds from one form to another which suggested the name given to the observing instrument. In general the complexity of the figure increases with the acuteness of the exciting sound. With low notes a comparatively simple arrangement of a few rings and pairs of vortices occupies the film. As the pitch rises, the separate parts of the figure diminish in size and increase in number, so that the whole field is covered with a regular pattern which is constantly growing more and more minute. With very shrill sounds the pattern can only be made out by using a magnifyingglass.

Effects of Quality.- These are easily observed by employing unison organ-pipes of different timbres, e.g., treble C's belonging to stopped and open diapasons, claribella, and hautbois, respectively. By sounding them consecutively in the above order, figures rapidly increasing in complexity are obtained.

Prominent among differences of quality are those which distinguish vowel-sounds of the human voice sung successively on one and the same note. Marked corresponding differences of colour-figure are recognisable in many instances, but $I$ have not at present succeeded in extending the observation to all the European vowel. sounds.

Effects aue to Direction of Vibration.-The best mode of observing these is to strike a tuning-fork, and hold it with one of its prongs close to the surface of the film.

By moving the fork it is easy to show that both the axis of symmetry, and to some extent also the form, of the colour-figure thus produced, are dependent on the position of the fork with respect to the film, and therefore on the direction in which the exciting vibrations impinge upon it. The steady bands of a figure obtained by this method shift to and fro upon the film in obedience to the fork's movements, almost as though under a magnetic influence resident in its prongs.

Resultant Figures due to Combined Sounds.-If the sounds of two tuning-forks are separated by a considerable interval of pitch, say an octave, they will generate, when alternately applied to the same film, very different figures. When both are applied together there results a figure different from either of those due to each fork by itself. It is in fact a compromise between the two. In order to convince himself of this the experimentor should first get the forms of the component figures well into his memory by repeatedly producing them, and then watch the effect, on some one band in either figure, of mixing the two sounds in various degrees of relative intensity. Let us suppose that fork I produces figure I, and fork 2 figure 2 , respectively, and that a band in figure $\mathrm{I}$ is selected for observation. Then if fork $\mathrm{I}$ be struck sharply, and fork 2 weakly, the band will alter its form so as to exhibit a slight approach to the arrangement in the corresponding part of figure 2. As the note of fork 2 is more loudly sounded this approach will be more decided. If fork 2 is made preponderant the result will be the arrangement of Fig. 2 with some modification towards that of figure $I$. The same thing holds good for the rotating portions of the figures. Complex colour-flows are seen to result from a compromise between simpler component vortices.

Effect of Beats. - When two sounds of very nearly the same pitch coexist, slow fluctuations of intensity called "beats" are known to be produced. If a film is exposed to the simultaneous action of two sounds so related, the fixed parts of the resulting figure take up a swaying motion about their mean position, each complete oscillation synchronising exactly with one entire beat. The vortices show, in general, an increased speed of rotation during one half of each beat, and a diminished speed during the other half. But in particular cases a bolt forward every alternate half-beat seems to be followed by intermediate quiescence, or the direction of motion may be actually reversed, so that a vortex rotates positively during one half-beat and negatively during the next.

Representation of Dissonance.-When the beats become too rapid for separate recognition, and coalesce into the effect which we call discord, the colour-figure presents a tremulous appearance, like that shown by the tip of a singing gas fame. Prof. Helmholtz has remarked how unpleasant is the impression which a flickering light makes upon the eye, and pointed out its analogy to the effect of rapidly intermittent sounds on the ear. In the present experiment, acoustical and optical dissonance are exhibited in a direct and interesting connection.

As the phenomena described in the above article admit of such facile reproduction in all their beauty of form and splendour of hue, I have thought it needless to attempt illustration by diagrams, which could convey but an inadequate notion of the former, and none at all of the latter.

Trinity College, Cambridge, March 6

SEDLEY TAYLOR

\section{REFLECTION OF LIGHT ${ }^{1}$}

PLACE the heliostat in position, and bring a slender beam of light into the darkened room. Then get a small looking-glass, or hand-mirror, and a carpenter's steel square, or a sheet of stiff paper, having perfectly square corners. Hold the mirror in the beam of light. At once you see there are two beams of sunlight, one from the heliostat and another from the mirror. Hold the glass toward the heliostat, and you will see this second beam going back toward the window.

This is certainly a curious matter. Our beam of light enters the room, strikes the mirror, and then we appear to have another. It is the same beam, thrown back from.

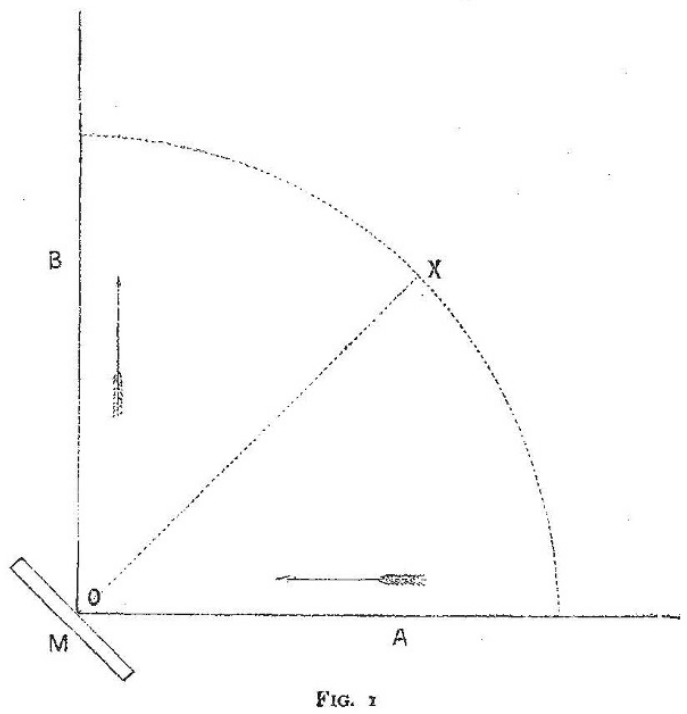

the glass. This turning back of a beam of light we call the reflection of light.

Place a table opposite the heliostat, and place the mirror upon it, against some books. Turn the mirror to the right, and the second or reflected beam of light moves round to the right. Turn the glass still more, and the beam of light will turn off at a right angle, and there will be a spot of light on the wall at that side of the room. Now bring the carpenter's square or the piece of square paper close to the mirror, so that the point or corner wil touch the glass just where the sunlight falls upon it. Now

"From a forthcoming volume of the "Nature Series"-- "Light: a Series of Simple, Entertaining, and Inexpensive Kxperiments in the Phenomena of Light, for the Use of Students of Every Age," by Alfred M, Mayer and Charles Barnard. 
one edge of the square is brightly lighted by the sunbeam, and if the mirror is placed at an angle of forty-five degrees with the sunbeam, the other edge of the square is lighted up by the second beam.

In Fig. I, A is the beam of light from the heliustat, and $\mathrm{B}$ is the beam reflected from the mirror, that is marked $M$. To make this more simple, we call the first beam the beam of incidence, and we say that it travels in the direction of incidence, as shown by the arrow. The second beam, marked A, we call the beam of reflection, and the course it takes we call the direction of reflection. The point marked $o$, where the light strikes the mirror, is called the point of incidence.

In the diagram is a dotted line representing a quarter of a circle reaching from the beam of incidence to the beam of reflection. A quarter of a circle, as you know, is divided into ninety degrees. Another dotted line extends from $\mathrm{O}$ at the mirror to $\mathrm{x}$ on the quarter-circle, and divides it into two parts. Half of ninety is forty-five, and hence the mirror stands at an angle of forty-five degrees with both beams of light. Now the line A and the dotted line reaching from $\mathrm{O}$ to $\mathrm{x}$ make the angle of incidence, and the angle between $\mathrm{B}$ and the line from $\mathrm{O}$ to $\mathrm{X}$ is the angle of reflection; and the curious part of this matter is, that these two angles are always equal. Here they are both angles of forty-five degrees.

Move the mirror about in any direction, and measure the angles of incidence and the angles of reflection, and these angles will always be exactly equal.

If you look at the diagram you will see that the mirror is at an angle of 45 degrees with the beam of incidence, and that the beam of reflection is at an angle of ninety

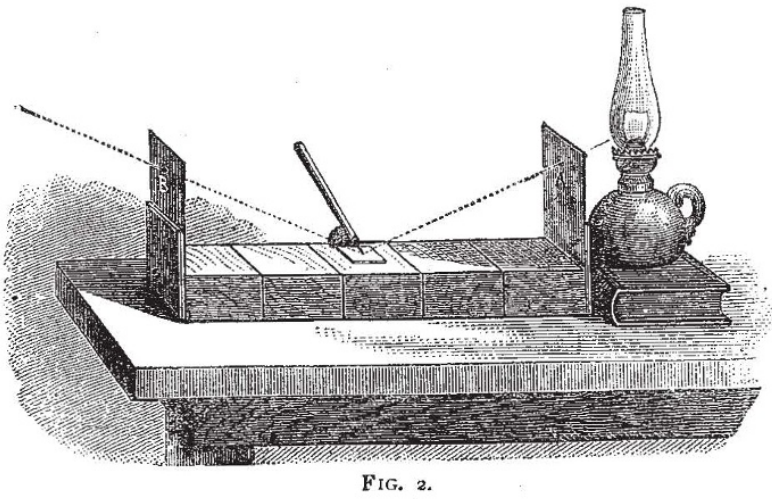

degrees with the incident beam. Hence, if the mirror is tilted through a certain angle, the reflected beam is tilted through twice this angle. For instance, if the mirror is moved $r$ degree, the beam of reflection moves 2 degrees. Place the mirror at an angle of $22 \frac{1}{2}$ with the beam of incidence, and the beam of reflection is at angle of 45 . Move the mirror to an angle of $67 \frac{1}{2}$, and the beam of reflection will move round to an angle of 135 degrees.

Fig. 2 represents the two postal-cards fitted on blocks of wood that we used in a former experiment, and the three blocks of wood we cut out at that time. The five blocks are placed close together in a line, and with the postal-cards at the ends. A lighted lamp is placed near one of the cards, and on the middle block is a small piece of window-glass that has been painted with black varnish. A single coat of black varnish on one side of the glass is all that is required to give us the black mirror needed in this experiment. Place the lamp close to the card in such a position that the flame will be just on a level with the hole in the card. If the lamp is not convenient the blocks and cards may be placed upon a table facing a north window in full daylight.

When everything is ready look through in the postalcard marked $\mathrm{B}$, down upon the black mirror, and on it you will see a single spot of light, the reflection from the lamplight or the light from the window shining through the hole marked $\boldsymbol{A}$ in the drawing. Get the needlepointed awl and place it so that the point will just touch the spot of light in the black mirror, and then fasten the awl in this position with a piece of wax, as represented in the picture.

You will readily see that this experiment is the same as the last. Again we have a beam of light reflected from a mirror. The beam of incidence passes through the postal-card at $\mathrm{A}$ and finds its point of incidence on the mirror, and the beam of reflection extends from the point of incidence to the second card at $B$.

Take a sheet of stiff paper 10 inches $\left(25^{\circ} 4\right.$ centimetres) long, and about 4 inches (Io centimetres) wide, and hold it upright between the two cards, with the bottom resting on the mirror. With a pencil make a mark on the edge of this at the point of incidence marked by the awl, and at the hole in the card where the beam of incidence enters, and marked $\mathrm{A}$ in the drawing. Draw a line between these two points and you have an angle formed by this line and the base of the paper. This angle marks the angle of incidence. Put the paper on the blocks with the ruled line toward the card $\mathrm{B}$, and you will find that the line fits here equally well. It now extends from the point of incidence to $B$, and proves that this angle is the same as the other, that both sides are alike, and that the angle of incidence and the angle of reflection are equal.

Take out the block in the middle and move the others nearer together till they touch. Repeat the experiment: make a measurement with a piece of paper as before, and draw a line on it from the point of incidence to either of the holes on the cards, and then compare the angles thus found, and in each case they will be exactly alike. 'Take out another block and try it again, and you will reach the same result.

These experiments show us that there is a fixed law in this matter, and the more we study it the more we are convinced that it has no exceptions.

\section{Experiment in Multiple Reflection}

Choose a south room on a sunny day and close the blinds and shutters at all the windows save one, and at this window draw down the curtain until only a narrow space is left at the bottom. Close this space with a strip of thick wrapping-paper, and then cover the rest of the window with a blanket or shawl so as to make the room perfectly dark. Then cut a round hole the size of a fivecent piece in this paper, and through this hole a slender beam of sunlight will fall into the darkened room.

Bring a hand-mirror into this beam of light and the beam of reflection will make a round spot of sunlight on the wall above the window. This spot of light is a picture of the sun thrown by the mirror upon the wall. Hold the mirror at an oblique angle in the sunbeam and direct the beam of reflection upon the opposite wall. Now there are several reflections, brilliant spots of light. If the spots of light do not stand out sharp and clear, turn the mirror slowly round and you will soon find a position for the glass that will give six or more reflections.

How does it happen that a common looking-glass can thus split a single sunbeam into several beams? If you touch a pencil to a mirror you will notice that while the point of the pencil touches the glass the point of the reflected pencil seen in the mirror does not meet the point of the real pencil, and that there is a little space between them. The reflection we see in the glass is from the smooth surface of the quicksilver at the back of the glass, and the space between the reflection and the pencil is filled by the glass.

Hold a sheet of common window-glass before a lighted lamp or candle, and you will see a faint reflection of the flame in the glass, and at the same time you can readily see through the glass. This shows us that the outside 
of any piece of smooth glass will reflect light, and our experiment is designed to show a still more curious matter.

1. Fig. 3 represents the single beam reaching the point of incidence ne outside of the mirror at $O$, and reflected to the wall at $\mathrm{I}$. Part of the light goes through the glass to $\mathrm{B}$, and here is another point of incidence, and a new beam of reflection is thrown through the glass to the wall at 2. If you look at the reflections on the wall, you will see that the second spot of light is the brightest. This comes from the quicksilver, for, as this is a better reflector than the glass, it sends out a brighter beam of reflection. When this second beam of reflection passes through the glass, a part of its light is reflected from the under side of the surface, and is turned back

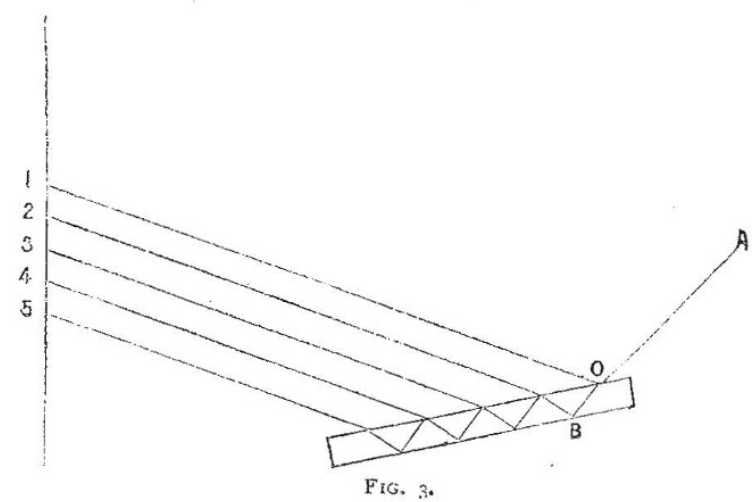

against the quicksilver again. Once more it is reflected, and a new beam of reflection makes number 3 . The drawing shows the path these beams of light take in the glass, and the quivering spots of light on the wall show how one beam of light may be reflected again and again in different directions. If the reflector was perfect and returned all the light, these multiple reflections might be repeated many times over; but every time light is reflected from any bright surface a part of the light is lost, and thus each reflection grows fainter and fainter till the light is spent. Look at the multiplied reflections on the wall, and you will see that the first reflection from the glass is bright, and that the second, from the quicksilver at the back of the glass, is brighter still; and that the others grow fainter and fainter till all the light is spent, and the reflections disappear.

\section{Second Experiment in Multiple Reflection}

Light a lamp and place it on a table, and get the two postal-cards and the blocks that we used in the experiment in reflection. With a sharp knife cut a slit in one card, just at the pin-hole, about $\frac{3}{4}$ inch (I9 millimetres) long and ${ }_{2}$ inch ( 1 millimetre) wide. Then place this card close to the lamp, as in the other experiment, and set up the other card about fifteen inches away from it. Then lay a looking-glass on the table between the two. Look at Fig. 2, and arrange the cards as there represented, and put the mirror in place of the blackened glass on the blocks. On looking through the small hole in the postal card (marked $B$ in the drawing); you will see in the mirror several bars of yellow light, placed one over the other. Again we have an instance of multiplied reflection. Instead of seeing the reflections thrown upon the wall, we can look down upon them and see them, just us they stand, each at its point of incidence on the glass and the quicksilver. Study these brilliant bars of light, examine the diagram carefully, and you will readily see that this experiment simply exhibits in a different manner the same thing that we saw in the last experiment.

\section{Experiment with Mirror on Pulse}

Get a small bit of looking-glass, about an inch 25 millimetres) square, and some wax. Warm the wax in the hand till it is soft, and then make three small pellets about the size of a pea. Put one of these on the back of the little mirror, near the edge and half-way between two corners. Place one at each of the opposite corners, so that the mirror will have three legs or supports placed in a triangle. Put the heliostat in place, and bring a small beam of sunlight into the dark room. If this is not convenient any beam of sunlight in a dark room (as in former experiments) will answer.

Turn back your coat-sleeve, and, while standing near the beam of light, place the little mirror on the wrist, with one of the wax legs resting on the pulse. Then bring the arm into the beam, so that the light will fall on the mirror. Hold the arm steady, and watch the spot of reflected light thrown upon the wall. See! It moves backward and forward with a curious, jerking motion. It is like the ticking of a clock, or like the bending of one's pulse. It is the motion of your pulse. The mirror moves with the pulse, and the beam of reflection thrown on the wall moves with it, and, though this movement is very slight, the reflection on the wall moves over a space of several inches, and we can see it plainly. In our first experiment in reflection we learned that when a mirror was moved to the right or left, the beam of light reflected from it moved also to the right or left, and each time through twice as great an angle as the mirror.

This experiment is a wonderfully interesting one, and may be tried with a number of boys or girls, and each may see the peculiar beating of his or her pulse pictured on the wall in the most singular and startling manner. If any of the persons whose pulse-beats are thus exhibited get excited, laugh at the exhibition, or are in any way disturbed, the change in the movement of their pulse will be quickly repeated on the wall, where a hundred people can see it.

\section{Experiment with Glass Tube}

Procure a glass tube, about $\frac{3}{4}$ inch (19 millimetres) in diameter and 12 inches (30'5 centimetres) long, and paint the outside with black varnish. If this is not convenient, cover the tube with thick black cloth, and fasten it down with mucilage, taking care to have the cloth square at the ends. Punch a hole in a postal-card with the sharp point of a pair of scissors, and with a knife make the

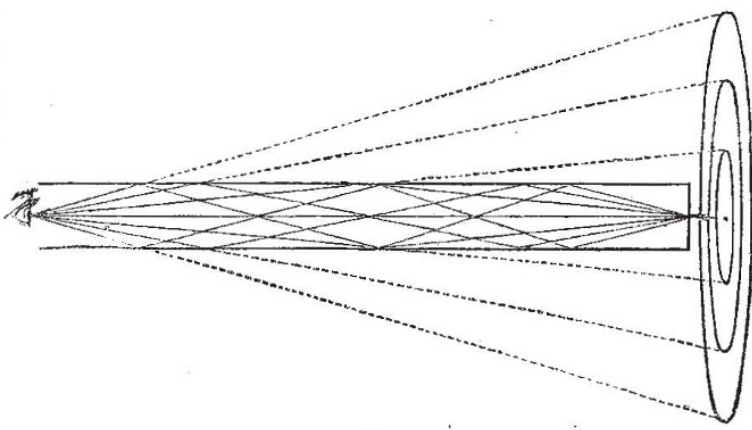

FIG. 4.

ragged edges of the hole smooth. Hold the card at one end of the tube so that the hole will come just at the centre of the opening, and then, while facing a window or a bright lamp, look through the tube with one eye, and you will see a spot of light surrounded by a number of beautiful rings.

Here we have another example of multiplied reflection. The light entering the tube through the hole in the card falls on the smooth surface of the interior of the tube, and appears to the eye in the form of rings. 
Fig. 4 represents a section of the [tube, and shows the paths the different rays of light take, and shows how each is reflected from side to side till they all meet in the eye. The dotted lines and the rings projected beyond the tube show how they appear to the eye. By studying this drawing carefully, and trying cross cuts and slits in the card in place of the single hole, you will get a very correct idea of repeated reflection, and find the tube a source of considerable amusement.

\section{Experments in Dispersed Reflection}

Get a small piece of black velvet or cloth and take it to a dark room where the heliostat will give us a slender beam of sunlight. If this is not convenient use a common beam of sunlight in a dark room, as in some of our former experiments. Hold the velvet in the hand between the fingers, and so as to leave the palm of the hand clear. Turn back the coat-sleeve so as to expose part of the white cuff, and then bring the velvet into the beam of sunlight. You will observe nothing in particular, for the black rough cloth does not reflect the light at all. Now move the hand so that the spot of light will fall on the palm. See what a pretty rosy glow of light falls on the wall! This is the reflected light from the hand. The skin is rough, and the light is diffused and scattered about, and instead of a bright spot of reflected light, as with a mirror, we have this glow spread all about on the wall and furniture. Now move your hand so that the sunlight falls on your cuff. Immediately there is a bright light shining on the wall and lighting the room with a pale bluish-white glare. Move the hand quickly so that the black cloth, the hand, and the white cuff will pass in succession the beam of light. Observe how the different things reflect the light in different degrees. The cuff is the smoothest and whitest, and gives the brightest reflection; the hand gives less light because it is less smooth; and the cloth, that has a very dark and rough surface, gives no reflection at all, and the spot of sunlight falling upon it seems dull and faint.

This experiment shows us something more in the reflection of light. A piece of glass, the surface of water, polished metals, ice, and all substances having very smooth surfaces, reflect light in one direction. The linen cuff also reflected light, but apparently in a very different manner from the mirrors we have been using.

Place a lighted lamp upon a table and lay a mirror before it, and you can see á clear and distinct reflection of the lamp and the flame pictured on the glass. Put a sheet of white paper before the lamp, and you can see only a confused spot of reflected light on the brightlylighted paper. Lay a freshly-ironed napkin or handkerchief before the lamp, and even the indistinct spot of light has disappeared, and the white cloth reflects light equally from every part.

These drawings are intended to show how light is reflected from different surfaces. The first represents a smooth surface, like glass, that sends all the beams in one direction, because the points of reflection for the beam are in the same plane. (See I, 2, 3, Fig. 5.)

The second drawing represents a slightly-roughened surface, like paper. Some of the points of reflection turn the light one way, some another, and the beam of reflection is no longer formed of parallel rays. They are scattered about, and the image they form is confused and indistinct. In the third drawing we have a rough surface, like cloth, and here the rays of the beam of reflection are scattered in every direction, and we can see no image.

It is in this manner that we are enabled to see the people and things about us. The light of the sun or a lamp falls upon them, and is reflected into our eyes, and we say we see the objects. Very few things reflect light so brightly that we obtain from them a reflected image of the source of the light, and we generally see only dispersed and scattered light, that does not blind or dazzle the eye, and enables us to look upon these objects with ease, and to readily see all their parts.

The clouds, the water, the grass, rocks, the ground, buildings, the walls inside, clothing and furniture, and everything we can see, reflect light in every direction again and again, and thus it is that all spaces, without and within, are filled with light so long as the sun shines. At night the sun sinks out of sight, and still it is light for
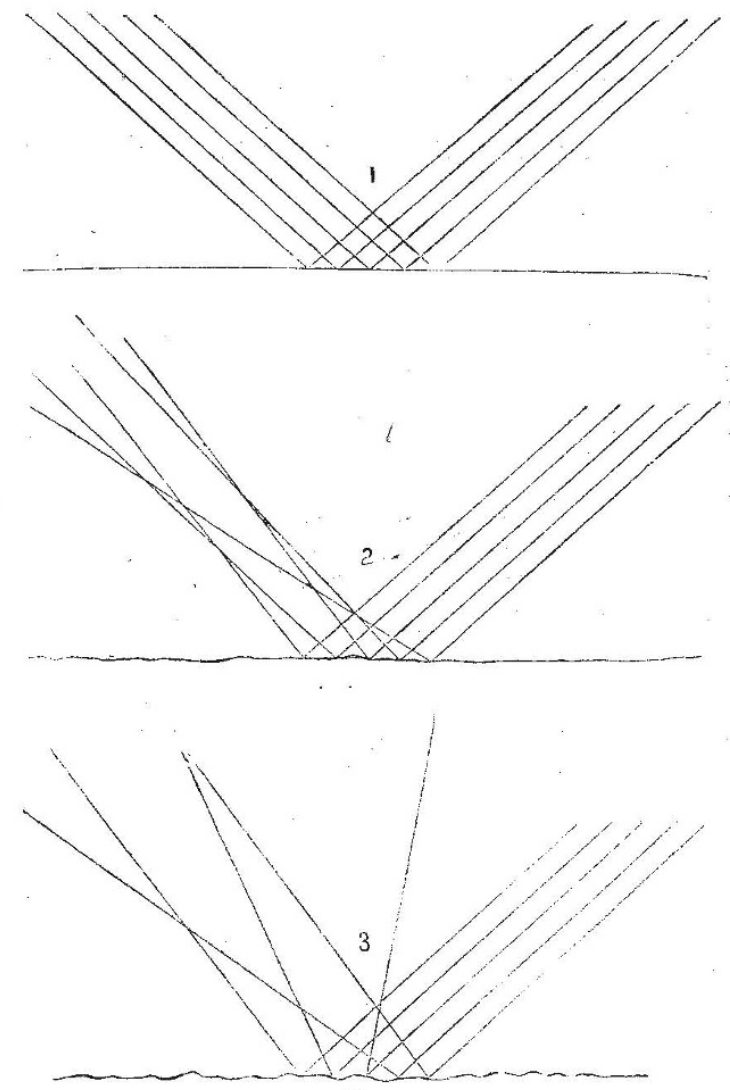

FIG. 5 .

some time after, for the sunlight is reflected from the sunset-clouds and the sky.

Sometimes, upon a summer's day, when broken clouds partly hide the sun, you will see long bars of dusky light streaming from openings in the clouds. These long bars are beams of sunlight shining upon dust and fine mist floating in the air, and we see them because each speck and particle reflects light in every direction.

\section{Experiment with far of Smoke}

Fig. 6 represents a large, clean glass jar, such as one sees at the confectioner's. It is standing upon a black cloth laid upon a table in a dark room, and on top of the mouth is laid a postal-card, having a slit, one inch (25 millinetres) long, and $\frac{1}{25}$ inch ( 1 millimetre) wide, cut in it. Above the jar is a hand-mirror, so placed that the beam of sunlight from the heliostat (or from a hole in the curtain) will be reflected downward upon the postal-card on top of the jar.

This simple apparatus is designed to show how light is reflected from small particles floating in the air. Set fire to a small bit of paper and drop it into the jar. Place your hand over the mouth of the jar 1 in a moment it will be filled with smoke. Whe te paper has burned out, put the postal-card in , so that the slit will be in the centre of the mouth of the jar. Let the beam of reflected light from the mirror fall on this slit. 
Look in the jar and will see a slender ribbon of light extending do $\mathrm{n}$ ad through the jar. Elsewhere it is quite dark and black. Here we see the light streaming through the opening in the card, and lighting up the particles of smoke in its path.

Take off the card, and let the reflected beam fall freely into the jar. The smoke is now wholly illuminated, and the jar appears to be full of light, and every part of the bottle shines with a pale-white glow.

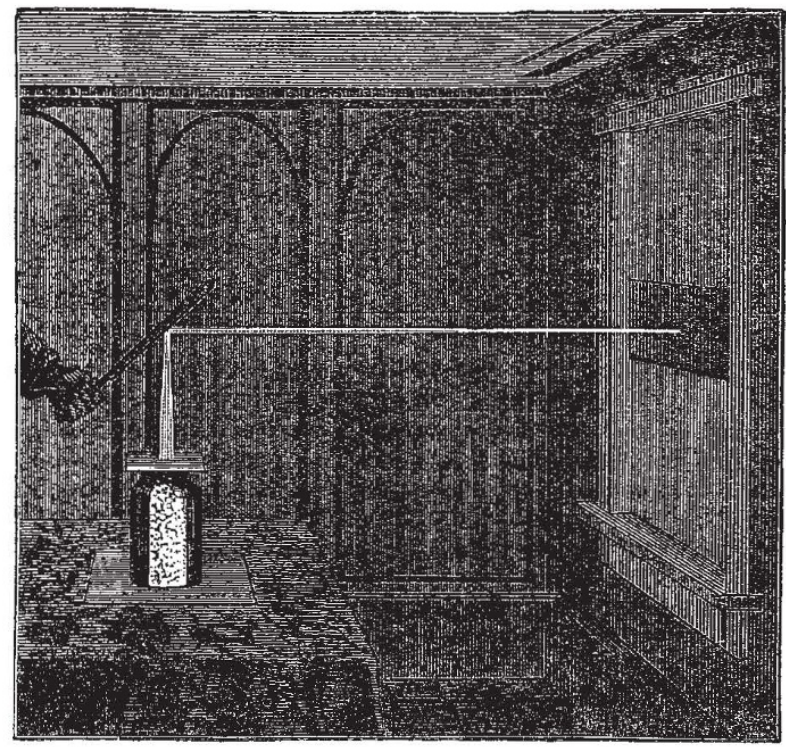

FIG. 6

Put the postal-card on again and let the light fall through the slit. The smoke has nearly all disappeared, and the ribbon of light in the jar is quite dim. Curious streaks and patches of inky blackness run through it. What is this? Nothing--simply nothing. The smoke is melting away, and the beam of light disappears because there is nothing to reflect it and make it visible.

This part of the experiment appears quite magical in its effects, and is exceedingly interesting.

\section{The Milk-and-Water Lamp}

Take away the jar and put a clear glass tumbler in its place. Fill this with water and throw the beam of reflected light down upon it, and the water will be lighted up so that we can easily see the tumbler in the dark. Now add a teaspoonful of milk to the water and stir them together. Throw the beam of light down once more. This is indeed remarkable. The tumbler of milk-andwater shines like a lamp, and lights up the room so that we can easily see to read by its strange white light. Move the mirror and turn aside the beam of light, and instantly the room becomes dark. Turn the light back again, and once more the glass is full of light.

Here the minute particles of milk floating in the water catch and reflect the light in every direction, so that the entire goblet seems filled with it, and the room is lighted up by the strange reflections that shine through the glass.

\section{AMERICAN GEOLOGIGAL, SURVEYS}

\section{MISSOURI}

THE State of Missouri boasts of abundant mineral wealth. Its seams of coal and its stores of iron and lead mark it out as one of the great centres of the future industry of the United States. Such a country might have been supposed only too anxious to have its mineral formations accurately mapped, so as to know exactly where and how its subterranean resources lie. Yet the history of its official action in this matter is by no means a gratifying one. As far back as the year 1849 a memorial was presented to the General Assembly of the State, praying for the formation of a Geological Survey, with liberal appropriations for constructing maps and publishing reports; for investigating causes affecting health, the agricultural capacities of different soils, the water system, and the rocks and minerals of the country. It was not until the early summer of 1852 that the State geologist, who, in response to this memorial, was appointed, began operations. Five annual reports, consisting for the most part of only a few leaves, appeared up to the year I86I, and, with one exception, contained mere statements of progress. Perhaps the Legislature began to think that the results obtained were not worth the expenditure to secure them. At all events, in $186 \mathrm{I}$ the Survey was disbanded. The authorities, however, seem to have been unwilling that the fruits of the long years of work of their geological staff should be lost ; they accordingly arranged to have them published, but finally abandoned this idea on account of the expense. For nine years nothing further appears to have been done in the matter. At last, in 1870 , the Legislature once more roused itself to consider the expediency of having the country properly explored and mapped. A "Mining, Metallurgical, and Geological Bureau "was now created, and a new State geologist was appointed. This arrangement, however, not proving satisfactory, the act was amended next year, but soon thereafter the State geologist resigned, and Mr. R. Pumpelly took his place. The body by which the geological work of the State was controlled, now called the "Bureau of Geology and Mines," consisted of a board of five managers, with a staff formed of a State geologist, an assistant palæontologist and geologist, an assistant chemist, and such additional assistance as might be possible within the limits of an annual appropriation of $\mathrm{IO}, 000$ dollars.

By the spring of 1872 a more liberal spir it had appeared in the assembly. An additional chemical assistant was allowed, and the annual vote was raised to 20,000 dollars. The Survey now set to work with prodigious vigour. $\mathrm{Mr}$. Pumpelly and his associates undertook an extensive exploration of the iron and coal districts, while the chemists were busy analysing the minerals sent into them from the field. By the end of the year a large mass of information bad been collected, and as the liberality of the Legislature had shown no sign of waning, a large appropriation was asked for the publication of the results obtained in 1872 , and another grant for the issue of the still unprinted reports of previous years. Both these appropriations, amounting to 9,000 dollars in the one case, and 3,000 dollars in the second, were voted. Accordingly two volumes duly appeared next year. The Report for 1872 was sumptuously printed and illustrated. Moreover, it was accompanied by a monstrous atlas of chromo-lithograph maps and sections. Some parts of the coal-fields were carefully illustrated by sections to show the structure of the areas and the relative positions of the seams in different districts. Perhaps some of these sections were on a needlessly large scale. Certainly the whole atlas was issued in a style so luxurious as to suggest that the Legislature must not only have become more liberal, but must be anxious to atone for former delinquencies by an almost extravagant expenditure in print and paper.

But this golden age was not destined to last. Mr. Pumpelly resigned, very shortly after the appearance of his meritorious though costly volumes. His successor, Mr. G. C. Broadhead, who had previously acted as chief assistant-geologist, found the fund at his disposal so depleted by the heavy expenses of the winter and spring of I 873 , that he had to reduce his field-staff. The Board of 